\title{
NIQAB SEBAGAI FASHION: DIALEKTIK KONSERVATISME DAN BUDAYA POPULER
}

\author{
Putri Aisyiyah Rachma Dewi, Awang Dharmawan ${ }^{2}$ \\ ${ }^{1,2}$ Program Studi Ilmu Komunikasi, Universitas Negeri Surabaya \\ Jalan Ketintang, Surabaya 60231, INDONESIA \\ Email: putridewi@unesa.ac.id
}

\begin{abstract}
ABSTRAK
Penelitian ini berfokus pada bagaimana niqab (cadar) diwakili di media sosial oleh penggunanya (niqabis). Niqabis di Indonesia memiliki pertumbuhan yang signifikan dalam dua tahun terakhir, mereka juga mulai menunjukkan eksistensinya dalam masyarakat Indonesia yang heterogen. Di sisi lain, penerimaan publik terhadap niqab sangat beragam, ada yang menerimanya sebagai bentuk praktik keagamaan, tetapi banyak orang menolak niqab karena melihatnya sebagai praktik budaya belaka, sementara yang lain sangat menolak niqab karena identik. dengan nilai-nilai radikalisme agama dan terorisme. Karena penerimaan yang beragam ini, niqab di Indonesia telah dimodifikasi dan memiliki penampilan yang berbeda dari asalnya. Niqabis, sebagai bagian integral dari kelompok Muslim perkotaan, mencoba mencampurkan nilai-nilai religiusitas dan modernitas. Dan niqab sebagai mode menjadi produk budaya material di mana keduanya saling terkait. Melalui metode semiotik terungkap bahwa mengunggah foto niqabis Instagram menjadi penanda bagaimana sintesis dari dua wacana itu terjadi. Ada dua foto yang menjadi objek penelitian, yang pertama adalah niqabis yang berdiri sendiri dan yang kedua adalah ketika dia berinteraksi dengan temannya di ruang publik. Kedua foto ini dipilih untuk melihat bagaimana Niqabis menafsirkan dirinya sebagai individu dan sebagai bagian dari kelompok sosial komunitas. Hasil penelitian menunjukkan bahwa niqab bukan penanda tunggal, itu dibagi dengan spidol lain seperti merek-merek fashion terkenal, warna pop, dan kegiatan dalam foto. Semua objek menunjukkan bahwa menjadi niqabis tidak berarti harus terasing dari kereta modernitas, lebih jauh lingkungan sosial menerimanya secara alami sebagai penerimaan dari anggota masyarakat lainnya.
\end{abstract}

Kata kunci: Muslim perkotaan ; niqab; budaya populer; konservatisme agama.

\begin{abstract}
This research focuses on how the niqab (veil) is represented in social media by its users (niqabis). Niqabis in Indonesia have significant growth in the last two years, they also began to show their existence in heterogeneous Indonesian society. On the other hand, public acceptance of niqab is very diverse, there are those who accept it as a form of religious practice, but many people reject Niqab because it sees it as a mere cultural practice, while other extremely reject niqab because it is synonymous with the values of religious radicalism and terrorism. Because of this diverse acceptance, niqab in Indonesia has been modified and has a different appearance from its origin. Niqabis, as an integral part of the urban Muslim group, tried to mix the values of religiosity and modernity. And niqab as a fashion became a product of material culture where both of them are intertwined.Through the semiotic method it was revealed that uploading photos of Instagram's niqabis became a marker of how the synthesis of the two discourses took place. There are two photographs being the object of research, the first is niqabis which is stand alone and the second is when she's interact with her friend in public space. These two photos were chosen to see how Niqabis interpreted itself as an individual and as part of a community social group. The results of the study show that niqab isn't single signifier, it is shared with other markers such as famous fashion brands, pop colours, and the activities in the photos. All of the objects show that being niqabis does not mean having to alienated from the wagon of modernity, further the social environment accepts them as naturally as acceptance of other members of society.
\end{abstract}

Keywords: Urban moslems; niqab; popular culture; religious conservatism.

\section{PENDAHULUAN}

Penelitian ini berlatar belakang fenomena pesatnya peningkatan pengguna cadar di Indonesia dalam kurun tiga tahun terakhir, khususnya di kelompok perempuan Islam urban. Namun demikian, kehadiran mereka di tengah masyarakat Islam sendiri mengalami penerimaan beragam, mulai dari yang mendukung hingga yang terang-terangan menolak. Penolakan terjadi karena bermacam alasan, pertama karena cadar dipandang sebagai praktik kebudayaan alih-alih praktik religiusitas. Kedua, cadar identik dengan nilai-nilai radikalisme dan eksklusivisme.

Di sisi lain, alam diri niqabis pun konservatisme semangat keberagamaan akan bertemu dengan nilainilai modernitas yang ada di sekitar mereka. Menurut Nani Rofhani dalam Jurnal Teosofi, sebagai kelompok urban middle yang cenderung menolak massifikasi budaya, para muslim urban menegasikan 
serbuan budaya populer dengan menunjukkan fundamentalisme keberagamaan. ${ }^{1}$ Mereka menolak modernitas, namun juga menginginkan penerimaan dari masyarakat akan pilihan menjadi fundamental yang mereka ambil.

Lebih jauh lagi, Nani menjelaskan bahwa komunitas muslim urban berusaha menunjukkan perilaku eksklusif yang berkiblat pada kota Makkah. Mereka memaknai Makkah tidak sebatas kiblat shalat belaka, tetapi juga penuntun perilaku sehari-hari. Itu sebabnya, mereka mengganti busana yang dikenakan dengan jubah (jalabiyah), celana jins diganti dengan celana tanggung di atas mata kaki (isbâl), dan sorban (imamah) sebagai pengganti topi. Mereka juga memanjangkan jenggot, sebagai salah satu ciri pengikut salafi. Sementara pada perempuan ditandai dengan baju lebar berwarna hitam atau abu-abu, dipadu dengan jilbab yang panjang dan penutup mata (niqab).

Kelas menengah muslim urban ini bertambah jumlahnya dari tahun ke tahun. ${ }^{2}$ Berdasarkan data yang dirilis oleh liputan6.com, sebuah perkumpulan muslimah bercadar, Niqab Squad Indonesia mengalami peningkatan jumlah anggota sangat signifikan dalam kurun 2017. Pada Februari 2017 ada 150 anggota, dan pada akhir Desember 2017 muslimah yang bergabung dengan mereka mencapai lebih dari 3000 orang. ${ }^{3}$ Artinya, pertumbuhan yang dialami melebihi angka $1000 \%$ dalam tempo kurang dari satu tahun. Komunitas lain yang juga mempertemukan niqabis satu dengan yang lain adalah Wanita Indonesia Bercadar (WIB) dan Muslimah Archery.

Sebelum tren penggunaan niqab, juga ada tren penggunaan jilbab lebar tanpa penutup wajah, mereka menyebut jenis yang demikian sebagai hijab. Penggunaan hijab juga menjadi tren pada awal tahun 2009 dengan motornya adalah Hijabers Community Indonesia (HCI). HCI pun bertumbuh karena alasan yang sama, yaitu upaya menampilkan citra lain dari hijab, yang lebih fashionable dan modern.

Berbagai komunitas tersebut tumbuh dan menjadi besar karena media sosial. Semua komunitas

\footnotetext{
${ }^{1}$ Nani Rofhani, Budaya Urban Kelas Menengah. Teosofi: Jurnal Tasawuf dan Pemikiran Islam Volume 3 Nomor 1 Juni 2013. Hal 181-210)

${ }^{2}$ Ichsan W. Saputro, Kemunculan Islamic Homeschooling \& Korelasinya dengan Kebangkitan Kelas Menengah Muslim di Indonesia. Jurnal el-Tarbawi Volume XI nomor 1 tahun 2018. Hal 103-114

${ }^{3}$ https://www.liputan6.com/news/read/3235074/menyingkap-hidupdi-balik-cadar
}

memiliki pola yang sama, yaitu memulai perkenalan dan interaksi dari dunia maya, kemudian kesepakatan untuk berkelompok dan berlanjut pada pertemuanpertemuan di dunia nyata untuk menguatkan kohesivitas kelompok. Salah satu tujuan yang ingin mereka capai adalah penerimaan masyarakat dan menghilangkan stigma negatif pada busana yang mereka kenakan, niqab. Untuk mencapai hal tersebut, mereka melakukan modifikasi pada niqab yang digunakan dan juga memilih ruang publik untuk melakukan pertemuan. ${ }^{4}$

Media sosial menjadi salah satu saluran niqabis untuk mencitrakan diri kepada publik. Instagram, menjadi platform digital yang banyak digunakan untuk menampilkan diri mereka ketika berniqab. Foto diri yang diunggah dan tagar atau narasi penanda yang mereka gunakan menunjukkan bagaimana juga menunjukkan upaya pencitraan tersebut. Tagar yang paling banyak digunakan dengan kata kunci "niqab" adalah \#niqabstyle dengan unggahan mencapai lebih dari 443.000, \#niqabbutterfly sejumlah 263.000 unggahan, dan \#niqabcantik yang digunakan oleh 23.000 foto. ${ }^{5}$

Penelitian ini menggunakan analisis semiotika untuk melihat kehadiran niqab sebagai budaya materiil alihalih simbol religiusitas penggunanya. Sebagai sebuah tanda budaya, niqab sarat akan konstruksi nilai, baik oleh pengguna maupun masyarakat sebagai pembaca tanda.

\section{TINJAUAN PUSTAKA}

\subsection{Niqab Sebagai Praktik Budaya}

Niqab atau cadar adalah varian model penutup kepala yang digunakan perempuan muslimah di Indonesia. Sebelum cadar, masyarakat Indonesia lebih dulu mengenal kerudung, jilbab, dan hijab. Perbedaan diantara ketiganya pada seberapa banyak anggota tubuh yang tertutupi dan juga luas penampang kain.

Rekaman sejarah Indonesia mencatat bahwa perempuan pertama yang mengenakan kerudung adalah seorang bangsawan di Makassar pada abad 17. Pada saat itu, penutup kepala berupa selembar kain yang dillilitkan dan masih memperlihatkan sebagian rambut perempuan. ${ }^{6}$ Pada catatan Dennys Lombard

\footnotetext{
${ }^{4}$ https://www.cnnindonesia.com/nasional/20180517094722-20298866/saat-cadar-jadi-stigma-niqab-squad-pilih-pakai-masker

${ }^{5}$ Sumber: Instagram yang diakses pada 6 Mei 2019

${ }^{6}$ Barbara Watson Andaya. 2006. The Flaming Womb: Repositioning Women in Early Modern Southeast Asia. USA: University of Hawai Press. Hal. 85
} 
justru mencatat adanya perempuan-perempuan Kerajaan Aceh yang mengenakan kain putih di atas kepala mereka pada kisaran waktu yang sama. ${ }^{7}$

Selanjutnya, kerudung mulai dikenal di masyarakat Jawa. Hadirnya organisasi perempuan berbasis agama pertama di Indonesia, Aisyiyah pada 1917 membuat kerudung semakin popular sebagai pilihan busana muslimah. Ada dua kerudung yang popular pada masa itu, yaitu kerudung yang menutup rapat rambut hingga leher (kerudung Nyai Walidah Dahlan, pendiri Aisyiyah) dan juga banyak digunakan adalah kerudung yang hanya menutup rambut semata, tidak menjulur panjang dan bahkan juga masih menampakkan leher dan sebagian rambut.

Ketika penggunanya semakin banyak, membawa ketakutan tersendiri bagi penguasa. Apalagi ketika Ayatollah Khomaeni berhasil menggulingkan Pemerintahan Iran melalui revolusi Iran di tahun 1979. Sebelumnya, mulai tahun 1930 Shah Iran melarang penggunaan jilbab, bahkan polisi akan melepas paksa perempuan yang mengenakan jilbab di wilayah publik. Jilbab menjadi simbol perlawanan perempuan kepada penguasa. Dan ketika rezim Pahlevi berhasil digulingkan, jilbab justru wajib dikenakan oleh seluruh perempuan Iran. ${ }^{8}$ Presiden Soeharto yang alergi dengan hal-hal yang berbau revolusi merasa takut jika semangat revolusi tersebut juga berkobar di Indonesia. Maka, tahun 1982 ia menerbitkan surat keputusan Presiden No. 052.c/Kep/ 0/82 yang isinya adalah larangan jilbab dikenakan di sekolah. Tahun 1991 larangan ini dicabut, dan jilbab boleh dikenakan di sekolah, meski untuk dokumen administratif sekolah masih tidak diperkenankan menggunakan jilbab. ${ }^{9}$

Fenomena cadar hadir seiring dengan masifnya pertumbuhan muslim urban di Indonesia. Muslim urban sendiri adalah kelompok masyarakat perkotaan menengah yang sedang bertumbuh semangat religisitasnya dan berusaha sebisa mungkin mengadopsi yang mereka yakini sebagai nilai-nilai keIslaman dalam kesehariannya. ${ }^{10}$ Mereka hadir dengan

\footnotetext{
7 https://thisisgender.com/jilbab-indonesia-dari-masa-ke-masa/ diakses pada 9 Mei 2019

${ }^{8}$ Artikel "Potret perempuan Iran, sebelum dan sesudah Revolusi Islam 1979" dimuat di https://www.bbc.com/indonesia/majalah47167017

9 https://historia.id/kultur/articles/membuka-bab-sejarah-jilbabPKkye

${ }^{10}$ Ichsan W. Saputro, Kemunculan Islamic Homeschooling \& Korelasinya dengan Kebangkitan Kelas Menengah Muslim di Indonesia. Jurnal el-Tarbawi Volume XI nomor 1 tahun 2018. Hal 103-114
}

beragam simbolisasinya, seperti berbagai produk berlabel halal atau syariah guna menunjang halal lifestyle, kajian keagamaan di dunia maya, dan tentu saja penggunaan cadar yang kian berlipat dari tahun ke tahun.

Menurut Nani Rofhani, selayaknya kelompok urban lain, yang disebut dengan "muslim urban" sejatinya kalangan kelas menengah yang memeluk agama Islam. Sehingga, karakteristiknya pun nyaris mengikuti pola kelompok middle pada umumnya, yaitu keinginan untuk membentuk identitasnya sendiri yang membedakan mereka dengan kelas bawah, dan membuka jalan mereka menuju kelas atas. Salah satu cara yang ditempuh adalah fundamentalisme beragama. Tingkat religiusitas adalah kendaraan yang paling masuk akal bagi kelompok ini. Sebab, dalam beragama, struktur dibentuk tak sekedar dari ekonomi semata tetapi juga kadar keimanan mereka yang tercermin dalam perilaku sehari-hari.

Untuk menunjukkan identitas tersebut, kelompok muslim(ah) urban percaya akan seruan kembali ke kantong budaya (enclave, yaitu metafora untuk puritanisme yang menolak modernitas. Kemudian, mereka akan membangun tembok moralitas (wall of virtue) berdasar nilai dan perilaku khas. Pada pandangan ini kantong dianggap sebagai batas antara yang baik dan buruk, in group - out group, kafir dan non kafir. Di luar kantong moralitas adalah para manusia kotor, tercemar, menular, dan berbahaya, sehingga harus dihindari. ${ }^{11}$

Namun, pada diri niqabis tak mudah untuk membentuk tembok moralitas ini. Salah satunya karena beragam nilai yang terlanjur melekat pada cadar, yaitu konservatisme dan radikalisme. McLarney yang menyatakan bahwa cadar adalah salah satu produk budaya patriarki dari gerakan Salafi. ${ }^{12}$ Kain yang menjulur menutupi nyaris seluruh tubuh perempuan itu membuat perempuan tidak memiliki kebebasan untuk melakukan apa-apa yang dilakukan oleh orang lain di kehidupan sosial mereka.

Penelitian lain oleh Eva F Nisa, yang menemukan para orang tua sangat berat hati ketika anak perempuan mereka memutuskan bercadar. Mereka mengkawatirkan masa depan, jodoh, dan pergaulan putri-

\footnotetext{
${ }^{11}$ Gabriel A Almond, R. Scott Appleby, dan Emmanuel Sivan. 2003. Strong Religious: The Rise of Fundamentalism around the World. London: The University of Chicago Press. Hal 33-37

${ }^{12}$ McLarney, E. The burqa in Vogue: Fashioning Afghanistan. Journal of Middle East Women's Studies, 2009 Vol. 5, no. 1. Hal 120
} 
nya sebab cadar identik dengan kelompok radikal dan teroris. Seringkali para orang tua meminta anak mereka untuk melepas cadarnya ketika kembali ke rumah. $^{13}$

Diana Nurliana, desainer busana muslimah yang mengenakan cadar dan salah satu pendiri komunitas Niqab Squad mengatakan bahwa niqab sesungguhnya bukanlah benda yang harus ditakuti. Niqab adalah simbol agama yang juga dapat mengadopsi nilai-nilai modern dan membuat kehadirannya lebih humanis. Sebagai sebuah fashion memiliki beragam model, mulai dari cadar Yaman, cadar poni, cadar bandana, eagle eyes, hingga half niqab. ${ }^{14}$

Ragam niqab tersebut merupakan upaya mereka untuk merasa nyaman dengan penutup kepala (hijab) yang mereka kenakan dimanapun mereka berada. Niqab yang selama ini identik dengan nilai-nilai konservatisme, kelompok salafi, radikalisme, dan terutama terorisme, berusaha mereka rekonstruksi menjadi sesuatu yang lebih dekat dengan modernitas dan budaya popular.

\subsection{Representasi}

Representasi merujuk pada konsep analisis teks, yang dalam paradigma ilmu biasanya termasuk dalam konstruktivisme. Teks dalam konsep representasi sendiri merupakan segala sesuatu yang diinterprestasikan dan membentuk suatu makna secara terusmenerus. Sehingga kemampuan representasi dalam teks ditentukan oleh pembuktian logis, ilmiah dari subjektivitas penafsir teks. Kategori teks ini bisa berbagai macam misalnya film, tayangan berita, video, musik, berita di media cetak, buku, perilaku manusia, dan apapun yang dapat diinterpresaikan dan menghasilkan representasi yang signifikan penting pada teks tertentu.

Dalam kajian media, representasi menjadi suatu hal yang penting untuk mengetahui representasi makna dari teks yang diproduksi oleh media massa tersebut. Dengan begitu konsep represntasi ini akan dapat membongkar kepentingan apa yang terjadi dalam produksi teks, dan relasi kuasa apa saja yang akan dibentuk ketika teks tersebut diproduksi secara massa dan menjadi suatu hal yang dirujuk dan dipercaya oleh khalayak media.

\footnotetext{
${ }^{13}$ Eva F. Nisa. Embodied Faith: Agency \& Obedience among Face Veiled University Students in Indonesia. The Asia Pacific Journal of Anthropology 2012. Hal. 366-381

${ }_{14} \mathrm{https} / / /$ wolipop.detik.com/hijab-update/d-3620452/cadar-ponihingga-mata-elang-mengenal-tipe-tipe-niqab-di-indonesia
}

Berdasarkan perkembangan teknologi media, saat ini konsep representasi dapat terjadi dalam kontenkonten yang beredar dalam media baru, baik itu portal berita, postingan di sosial media, portal film, dan jaringan online apapun yang memproduksi konten dapat dianalisis teksnya. Penetrasi teknologi media baru yang semakin tinggi, mengalahkan media massa lainnya, menjadi keunikan tersendiri untuk Dianalisis. $^{15}$

Analisis pendahulu tentang representasi ini juga pernah dijelaskan oleh beberapa tokoh yang membuat kajian semiotika atau semiologi. Semiotika yang diperbincangkan sejak era filsafat Yunani, secara etimologis berasal dari bahasa Yunani, semeion yang artinya tanda. Secara terminologis, menurut Eco, semiotika dapat didefinisikan sebagai ilmu yang mempelajari sederetan luas objek-objek, peristiwaperistiwa, dan seluruh kebudayaan sebagai tanda. Pakar lainnya juga memberikan definisi untuk istilah semiotika atau semiologi. Dalam definisi Saussure, semiologi adalah sebuah ilmu yang mengkaji kehidupan tanda-tanda di tengah masyarakat. Tujuannya adalah untuk menunjukkan bagaimana terbentuknya tanda-tanda beserta kaidah-kaidah yang mengaturnya. $^{16}$

\section{METODE}

Penelitian ini menggunakan paradigma konstruktivisme dengan menggunakan metode semiotika. Peneliti menggunakan perangkat semiotika Charles Sanders Pierce untuk melihat bagaimana sintesis konservatisme dan modernitas direpresentasikam dalam unggahan Instagram dari niqabis. Bagi Pierce system penandaan meliputi tiga unsur, yaitu sign, object dan interpretant. Sementara, berdasarkan relasi antara object dan interpretant, tanda dibagi menjadi tiga yaitu: yaitu ikon, indeks, dan symbol. Unit analisis dalam penelitian ini adalah unsur-unsur visual dalam foto, tagar, dan juga narasi foto (caption) yang digunakan dalam unggahan.

Ada dua foto yang akan dianalisis, yang pertama adalah foto seorang diri perempuan berniqab dan kedua foto perempuan berniqab dengan kawankawannya. Pemilihan kedua tema tersebut untuk melihat bagaimana niqabis merepresentasikan diri (yang berniqab) dan lingkungan sosial yang ia miliki.

\footnotetext{
${ }^{15}$ Pawito. 2010. Komunikasi Politik. Yogyakarta: Jalasutra

${ }^{16}$ Roland Barthes, 2007. Membedah Mitos-Mitos Budaya Massa. Yogyakarta: Jalasutra
} 


\section{HASIL DAN PEMBAHASAN}

\subsection{Identitas diri Niqabis}

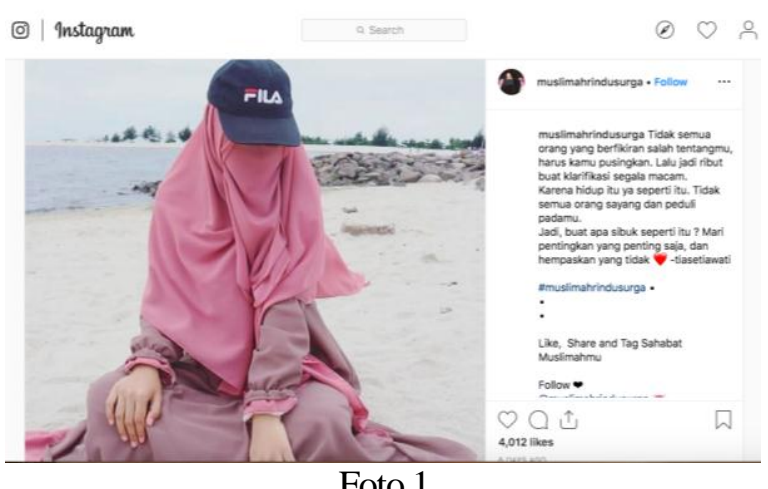

Foto 1

Pada foto pertama, tanda visual yang hadir adalah: seorang perempuan mengenakan niqab berwarna merah muda dan baju berwarna senada. Perempuan tersebut juga mengenakan topi bertuliskan "FILA". Ia tidak benar-benar mengenakan niqab, melainkan jilbab besar yang kemudian sebagian kain ia gunakan untuk menutup wajah. Perempuan tersebut duduk bersila di pasir putih tepian pantai. Wajahnya separuh menunduk, sehingga topi yang dikenakan menutupi mata yang tak tertutup oleh kain. Dalam foto tersebut, suasana pantai tampak lengang dan bersih.

Warna merah muda, topi FILA, pantai, dan caption (narasi) menjadi penanda kunci dalam foto pertama. Perempuan yang menggunakan nama akun @muslimahrindusurga itu berusaha mempertemukan nilai modern dalam dirinya dengan empat penanda tersebut.

Niqab di Negara asalnya, Arab Saudi cenderung berwarna gelap polos dan tidak berwarna-warni. Fungsi niqab untuk "menjaga" keindahan perempuan agar terlindung dari niat dan perilaku jahat pria-pria di sekeliling perempuan. Untuk itulah niqab dibuat dengan warna yang tidak eye catching. Sebuah larangan bagi perempuan muslim konservatif menarik perhatian laki-laki dengan sengaja. Pada foto di atas, niqab keluar dari pakem asalnya. Jika biasanya niqab berwarnanhitam atau biru gelap, maka niqab yang dikenakan oleh @muslimahrindusurga berwarna pink. Merah muda masuk pada kelompok warna pastel (pastel colors), yaitu kelompok warna yang memiliki saturasi rendah dan identik dengan kelembutan. Warna baju dan cadar merah muda cenderung pada apa yang disebut sebagai "dusty pink", tone ini menjadi salah satu tren warna fashion 2019 menurut laman Vogue dan Harper. Modern dan lembut adalah makna yang muncul dari penggunaan warna dusty pink pada niqab yang dikenakan.
Kedua, munculnya tulisan Fila dalam gambar, yaitu pada topi yang dikenakan model. "FILA" jamak diketahui sebagai merk dagang internasional untuk produk sport dan fashion yang berasal dari Italia. FILA hadir sebagai representasi modernitas barat. Ia hadir menegasikan nilai konservatif dari jubah dan cadar. Tak lazim seorang perempuan berniqab mengenakan topi. Namun, dalam foto ini batas kelaziman tersebut ditawar sehingga memunculkan makna menjadi seorang muslimah bercadar bukanlah halangan untuk tampil beda dan kekinian.

Pantai, yang menjadi lokasi pengambilan gambar mewakili konsep "leisure" atau waktu senggang yang lazim digunakan untuk bersenang-senang. Leisure hanya dimiliki oleh mereka yang telah mapan secara ekonomi (middle up), sebab mereka tidak lagi sepanjang waktu harus berpikir memenuhi kebutuhan primer mereka.

Pertentangan modernitas dan konservatisme juga sebenarnya dirasakan oleh pengunggah foto. Dalam narasi yang ia tulis, "Tidak semua orang yang berfikiran salah tentangmu, harus kamu pusingkan. Lalu jadi ribut buat klarifikasi segala macam. Karena hidup itu ya seperti itu. Tidak semua orang sayang dan peduli padamu. Jadi, buat apa sibuk seperti itu? Mari pentingkan yang penting saja, dan hempaskan yang tidak" tampak bahwa ia memiliki kesadaran terjadinya penolakan lingkungannya terhadap pilihan bercadar. Kerisauan tersebut hadir dalam benaknya, dan ia berusaha menyingkirkan pikiran tersbut. Ia berusaha enjoy di dunia yang tidak begitu menerimanya. Sikap enjoy dan cuek atau acuh menjadi ciri khas generasi milenial, generasi terbaru peradaban manusia di era digital.

\subsection{Niqabis dan Lingkungan Sosial}

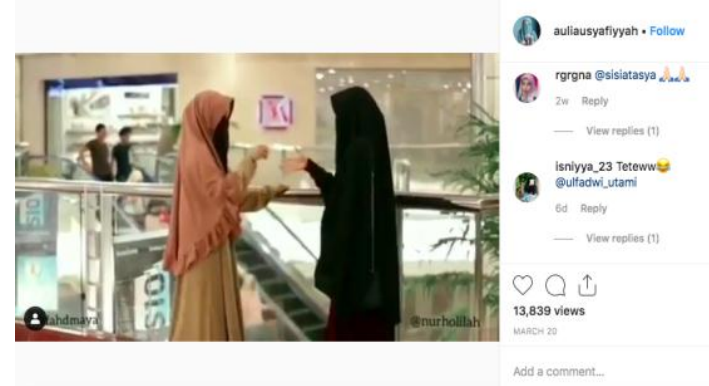

Foto 2

Dalam pesan kedua, unggahan dibuat oleh akun @ auliasusyafiyyah. Unggahan ini sebenarnya berupa video yang menunjukkan bagaimana kedua perempuan (pemilik akun dan kawannya) mengenakan cadar bermain toss tangan di sebuah pusat perbelanjaan. Mereka asyik tertawa dan menikmati permainan 
tersebut, meski ada orang berlalu lalang. Dalam pesan ini hadir sebagai penanda adalah warna niqab yang dikenakan, aktifitas, keberadaan orang lain dalam frame, dan juga latar lokasi pengambilan gambar.

Pada penanda pertama, perempuan kesatu mengenakan cadar berwarna hitam, baju berwarna marun tua. Sementara perempuan kedua memilih baju berwarna coklat muda dan jilbab berwarna coral peach. Meski warna yang dipilih perempuan kesatu cenderung berwarna gelap, namun permaianan warna yang lebih tampak berwarna masih berusaha ditampilkan pada baju yang dikenakan. Perempuan kedua jelas memilih warna pastel, seperti niqabis di foto pertama, yaitu coral peach yang bernuansa lembut dan feminine. Kehadiran dua warna yang kontras ini juga menyampaikan pesan bahwa niqab sebagai fashion pun memiliki ragam model. Memilih niqab yang gelap, bukan berarti menjadikan seorang muslimah menjadi kolot dan tak mampu bergaul. Itu hanyalah pilihan fasion, seperti halnya cadar berwarna coral peach yang lembut dan tren.

Aktifitas toss tangan yang dilakukan kedua perempuan tersebut menjadi symbol dari kelompok manakah mereka merasal. Toss tangan adalah aktifitas yang identik dengan milenial, toss tangan. Tawa lepas dan sikap cuek menegaskan identitas milenial yang mereka usung. Makna yang muncul adalah mereka nyaman meskipun berniqab, memiliki pergaulan sosial selayaknya perempuan lain. Para niqabis juga memiliki kawan dekat dan memiliki "ritual" yang lazim dilakukan oleh kelompok lingkaran persahabatan, yaitu toss.

Penanda lain adalah mall dan kehadiran pengunjung lain. Mall adalah sebuah situs modern tempat para manusia masa kini membelanjakan uang mereka. Niqabis bukanlah kelompok yang mengharamkan mall. Justru yang tampak adalah, mereka adalah kelompok yang sering masuk mall dan sudah merasa nyaman di dalamnya. Hal ini tampak dari bagaiamana mereka dengan santai dan menikmati bermain tos tangan. Para pengunjung mall pun tak ada yang memperhatikan dan menganggap mereka sebagai anomaly. Hal ini tampak dari nyaris tidak adanya orang yang memperhatikan aktifitas dua niqabis tersebut.

\section{KESIMPULAN}

Niqab secara sengaja dihadirkan secara kontrakdiktif dengan penanda-penanda lain untuk menunjukkan bahwa sebagai fashion, niqab tak ketinggalan gerbong modernitas yang tengah melaju. Niqab hadir sebagai sintesa antara tuntutan keberagamaan yang dinilai orang modern sebagai suatu hal yang kuno dengan konsep "kekinian" atau modernitas.

Penampilan adalah poin penting dalam setiap penanda perubahan era. Penampilan tubuh manusia melalui pakaian, dandanan, dan tingkah laku membuat pernyataan yang kuat tentang kelas, status, dan gender. Perubahan-perubahan dalam penampilan tubuh tersebut memberikan petunjuk bagi transformasi sosial yang lebih luas. Dan itu pula yang tengah dilakukan oleh para niqabis dengan unggahan-unggahan akun Instagram mereka.

Mereka ini adalah muslimah yang berasal dari golongan middle-up class, berpendidikan tinggi, dan memiliki pergaulan sosial baik. Niqab yang awalnya menjadi hambatan bagi perempuan untuk tampil (menarik) di wilayah publik, diubah sebagai kekuatan penampilan dan pembentukan karakter yang kuat.

\section{DAFTAR PUSTAKA}

Artikel "Potret perempuan Iran, sebelum dan sesudah Revolusi Islam 1979” dimuat di https://www. bbc.com/indonesia/majalah-47167017

Barbara Watson Andaya. 2006. The Flaming Womb: Repositioning Women in Early Modern Southeast Asia. USA: University of Hawai Press. Hal. 85.

Eva F. Nisa. Embodied Faith: Agency \& Obedience among Face Veiled University Students in Indonesia. The Asia Pacific Journal of Anthropology 2012. Hal. 366-381.

Gabriel A Almond, R. Scott Appleby, dan Emmanuel Sivan. 2003. Strong Religious: The Rise of Fundamentalism around the World. London: The University of Chicago Press. Hal 33-37.

Ichsan W. Saputro, Kemunculan Islamic Homeschooling \& Korelasinya dengan Kebangkitan Kelas Menengah Muslim di Indonesia. Jurnal elTarbawi Volume XI nomor 1 tahun 2018. Hal 103-114.

McLarney, E. The burqa in Vogue: Fashioning Afghanistan. Journal of Middle East Women's Studies, 2009 Vol. 5, no. 1. Hal 120.

Nani Rofhani, Budaya Urban Kelas Menengah. Teosofi: Jurnal Tasawuf dan Pemikiran Islam Volume 3 Nomor 1 Juni 2013. Hal 181-210)

Pawito. 2010. Komunikasi Politik. Yogyakarta: Jalasutra.

Roland Barthes, 2007. Membedah Mitos-Mitos Budaya Massa. Yogyakarta: Jalasutra.

https://www.liputan6.com/news/read/3235074/menyi ngkap-hidup-di-balik-cadar. 
https://www.cnnindonesia.com/nasional/2018051709 4722-20-298866/saat-cadar-jadi-stigma-niqabsquad-pilih-pakai-masker Sumber: Instagram yang diakses pada 6 Mei 2019.

https://thisisgender.com/jilbab-indonesia-dari-masake-masa/ diakses pada 9 Mei 2019. https://historia.id/kultur/articles/membuka-babsejarah-jilbab-PKkye

https://wolipop.detik.com/hijab-update/d-3620452/ cadar-poni-hingga-mata-elang-mengenal-tipetipe-niqab-di-indonesia. 